Revista de Filosofía

ISSN: 0034-8244

https://dx.doi.org/10.5209/resf.67419

\title{
Entre Nietzsche y Spinoza: estética afectiva desde la voluntad de poder
}

\author{
Sergio Casado Chamizo ${ }^{1}$
}

Recibido: 22 de enero de 2020 / Aceptado: 11 de abril de 2020

Resumen. Este artículo propone una interpretación estética de la relación entre los sistemas filosóficos de Spinoza y Nietzsche a partir una base ontológica común. Aunque sea difícil defender una lectura de Spinoza por parte de Nietzsche, si nos dirigimos a la mediación desde el pensamiento indio entre los pilares de sus respectivos sistemas, podremos fundar una relación entre la voluntad de poder y el conatus spinozista. El propósito de esta investigación es doble: por un lado, proponer una interpretación estética de la filosofía de Spinoza desde su sistema de los afectos y, a partir de ahí, apuntar al fundamento afectivo de esta estética desde la voluntad de poder nietzscheana.

Palabras clave: Nietzsche; Spinoza; voluntad de poder; conatus; estética de las pasiones; afecto; amor.

\section{[en] Between Nietzsche and Spinoza: Affective Esthetic from Will to Power}

Abstract. This article proposes an esthetical interpretation of the relationship between philosophical systems of Spinoza and Nietzsche from a common ontological basis. Although it is difficult to defend a reading of Spinoza by Nietzsche, if we move on to the mediation from Indian thought between the pillars of their respective systems, we can establish a relationship between the will to power and the Spinozist conatus. The purpose of this research is twofold: on the one hand, to propose an esthetical interpretation to Spinoza's philosophy from his system of affections and, from there, point to the affective foundation of this aesthetics from the Nietzschean will to power.

Keywords: Nietzsche; Spinoza; will to power; conatus; esthetic of passions; affections; love.

Sumario. 1. Sentido de una mediación; 2. Siguiendo las huellas. Entre una carta y un educador; 3. Voluntad creativa: lo que puede un cuerpo; 4 . Afectividad constructiva; 5 . Conclusiones; 6 . Referencias bibliográficas.

Cómo citar: Casado Chamizo, S. (2021): "Entre Nietzsche y Spinoza: estética afectiva desde la voluntad de poder", en Revista de Filosofía 46 (2), 293-312.

1 Universidad de Salamanca

sergio_poe@usal.es 


\section{Sentido de una mediación}

Los diversos estudios que han comparado el pensamiento filosófico de Spinoza y Nietzsche han sabido constatar, aún con las distancias entre el escenario donde Spinoza problematiza sobre Dios y el tiempo en que Nietzsche hace surgir su crítica contra toda teología, que no hay impedimento para proponer una lectura compensatoria entre ambas propuestas. Como tampoco impide que de este ejercicio surjan iniciativas sugerentes para quien se acerque a este debate. En sus respectivos textos, Deleuze propone el sistema de Spinoza como una «filosofía de potencias» ${ }^{2}$ y el de Nietzsche como una «filosofía de fuerzas». ${ }^{3}$ Así expresado no despierta un interés mayor que el de la analogía entre "potencia" y "fuerza", pero esto cambia cuando comenzamos a pensar las tesis que ambos autores esgrimen acerca del desarrollo de una reflexión sobre el cuerpo y las fuerzas que lo gobiernan.

Ante las diversas opiniones y formulaciones que los especialistas han defendido para proponer estos puntos de encuentro, debemos aclarar muchas cuestiones para no caer en interpretaciones poco pertinentes de difícil sustento. No debemos olvidar que la Ética de Spinoza supone una reformulación sobre la razón, el cuerpo y, fundamentalmente, sobre los afectos. Un itinerario como este guarda ciertos aires de familia con el desarrollo de la filosofía de la voluntad de Nietzsche y sus reflexiones estéticas: «lo esencial en el arte sigue siendo su cumplida consumación de la existencia, su producción de la perfección y de la plenitud»». ${ }^{4}$ Es decir, la culminación del impulso sensible a partir del potencial alcance del afecto. ${ }^{5}$ Pero no por ello estamos legitimados a decir que haya un nexo que el propio Nietzsche buscase sostener. Necesitamos remontarnos a algún sustento que nos permita proponer algo como lo que pretendemos.

Empezamos analizando un suelo común que se remonta a los albores del pensamiento y cuyos esquemas encuentran analogías en diversos sistemas filosóficos occidentales. Debemos recurrir a un esquema cuyas huellas estén presentes en el cuerpo de nuestros esbozos sobre la realidad y que, en este caso, encontramos en el pensamiento indio. ${ }^{6}$ Veremos en qué sentido establecemos esta relación cuando nos detengamos a analizar el origen de muchas de nuestras reflexiones y de sus constantes regresos para (re)definir sus posturas. Tal y como nos dice Edward Said: «El recuerdo del Oriente moderno entra en conflicto con la imaginación, hace que se vuelva a la imaginación, que es un lugar más propicio para la sensibilidad europea

\footnotetext{
Deleuze (2004), p. 38.

Deleuze (2016), pp. 73-74.

4 Nietzsche (FP IV, 14 [47], 2008), p. 522. Citaremos las obras de Nietzsche mediante las siguientes formulaciones: OC (Obras completas. Ed. Diego Sánchez Meca), seguido del volumen y el año de la edición que utilizamos; FP (Fragmentos póstumos. Ed. Diego Sánchez Meca), seguido del volumen, el número de referencia del cuaderno, el fragmento entre corchetes y el año; CO (Correspondencia. Ed. Luis E. Santiago Guervós), seguido del volumen, la carta y el año de la edición.

5 Véase E3P11s, pp. 224-226. Referenciamos las obras de Spinoza según las convenciones de Studia Spinozana: E (Ética), $\mathrm{n}^{\circ}$ de la parte, seguido de Definición (Def.), Axioma (Ax), Prefacio (Praef), Definiciones de afectos (AD) o Proposición (P) y, en su caso, Demostración (D), Escolio (s), Corolario (c) o Apéndice (A); TTP (Tratado teológico-político) y capítulo. TP (Tratado político), capítulo y parágrafo; $\mathrm{CM}$ (Pensamientos metafísicos); TIE (Tratado de la reforma del entendimiento); CT (Breve tratado de dios, el hombre y su felicidad), parte del libro (1, 2 o Praef) y el capítulo o apéndice (A); Ep. (Correspondencia) y número de la carta. Seguimos las traducciones de Atilano Domínguez en las ediciones de Alianza: E (2016), TP (2013), CT (1990), TIE, CM y PPC (2014) y Ep. (1988).

6 Véase Lenoir (2019), pp. 96-97 y Said (2012), p. 164.
} 
que el Oriente real»..$^{7}$ Apuntar a esto encuentra su sentido en las incursiones que se han propuesto a partir de la filosofía de Spinoza. No sería extraño proponer algún resto de esta presencia en un pensador como Nietzsche; un pensador, no lo olvidemos, que desarrolla su reflexión en el momento en que se está asimilando el pensamiento vedista en Europa por parte de Fichte y Schopenhauer. ${ }^{8}$

Si abrimos el espectro filosófico, sin llegar a formular interpretaciones sesgadas que no se adecúan a las intenciones de los autores, podemos encontrar en el (sub) suelo fértil de sus respectivos sistemas un sustrato común que permite desarrollar estas relaciones. A partir de ahí, nuestra intención en estas páginas pasa por llevar a los autores a comparecer ante tres pilares concretos: corporalidad, voluntad y afectividad; conceptos que están presentes en ambos, con puntuales diferencias, pero que, desde esta lectura, supondrá la introducción de fuertes contrapesos y así desarrollar una propuesta estética conjunta. Esta propuesta que presentamos no busca anular esos elementos, sino extraer una serie de propuestas estéticas que puedan surgir de sus semejanzas:

la ética de Spinoza se aproxima muchísimo a la estética nietzscheana. No hay parámetros trascendentales que indiquen qué es lo que debe hacerse, sino que las distintas valoraciones que rigen el comportamiento humano son creadas por los hombres para potenciar y perpetuar un determinado modo de vida, una forma de existencia. ${ }^{9}$

Plantear un espacio de problematización acerca de la posibilidad de hacer comparecer a ambos autores en sintonía, con una serie de elementos establecidos a priori, lleva implícito que debamos llevarlos al límite de sus construcciones para ver hasta qué punto permiten su excentricidad dentro de sus respectivos sistemas. Esta presentación comparativa tiene el propósito de dar lugar a una vía de interpretación con respecto a la forma de entender la creación artística y nuestra relación con ella desde la facticidad de nuestra existencia corporal, volitiva y afectiva ${ }^{10}$, sin que por ello adolezca de falta de fidelidad a las tesis de ambos autores. Se trata de entender que de este acercamiento entre ambos regímenes y desde la comparecencia sobre diversos aspectos comunes podremos llevar a cabo una formulación estética de esos principios compartidos.

\section{Siguiendo las huellas. Entre una carta y un educador}

A estas alturas, supone un tópico apuntar a esta problemática desde una lectura de Spinoza por parte de Nietzsche para abrir el debate acerca de una influencia spinozista en su sistema. Sin embargo, pocos han sido los que han seguido la pista de ese yacimiento en busca de alguna base con la que ambos parecen tener semejanzas. Desde estas lagunas podemos empezar a plantear los cimientos de nuestra investigación. En la famosa carta a Overbeck, Nietzsche dice:

\footnotetext{
Said (2012), p. 145.

8 Con respecto a la lectura y asimilación de los Upanishads por parte de Schopenhauer y de la posterior influencia, véase Maillard (2014), pp. 321-328.

9 Roldán López (2018), p. 97.

10 Deleuze (2016), p. 91.
} 
¡Estoy absolutamente asombrado, encantado! ¡Tengo un predecesor, y además de qué clase! Spinoza me era casi desconocido: que ahora haya sentido la necesidad de él ha sido un «acto instintivo». No sólo su planteamiento general coincide con el mío -hacer del conocimiento el afecto más potente-, sino que además me reconozco en cinco puntos fundamentales de su doctrina; este pensador, el más singular y aislado, es el más cercano a mí justo en estas cosas: niega la libertad de la voluntad-; los fines-; el orden moral del mundo-; lo no-egoísta-; el mal-aunque las diferencias, naturalmente, son enormes, tienen más que ver con la diversidad de las épocas, de la cultura y de la ciencia. In suma: mi soledad, [...] ahora al menos es una soledad de dos. ${ }^{11}$

Se puede precisar más o menos los conceptos a los que Nietzsche apunta para establecer su adhesión al pensamiento de Spinoza, pero son correctos en su planteamiento. Con esto la comparación sería muy sencilla: tendríamos una base perfecta sobre la que proponer un paralelismo entre ambos autores y, más aún, estaríamos ante la posibilidad de proponer una tendencia spinozista en el pensamiento de Nietzsche. Y, aunque no deja de ser curioso que el autor que viene a acabar con la tradición a golpe de martillo reconozca en la misma tradición y, más aún, en la tradición del racionalismo moderno de corte escolástico, ${ }^{12}$ el punto de apoyo sobre el que propinar sus primeros golpes, deja de serlo si comprobamos que el joven Nietzsche reconoce y alaba la influencia de la tradición. ${ }^{13}$ No sería necesario plantear un estudio comparativo alternativo para hallar los elementos que median entre ambos, si acaso solo para desarrollar algunos elementos y proponer una interpretación con la misma intención que la que nos proponemos. El problema surge cuando nos damos cuenta de que esta carta es la continuación de una misiva anterior. En esta Nietzsche solicita a Overbeck que le envíe una serie de libros, entre ellos, «el volumen de Kuno Fischer sobre Spinoza». ${ }^{14}$ Esto dice mucho, pero a la vez no supone nada.

Son pocas las evidencias que demuestran la lectura que Nietzsche hizo acerca de Spinoza en aquellas fechas, pero son suficientes para poder determinar el nivel de conocimiento que tiene sobre su sistema. ${ }^{15}$ Esto resalta cuando encontramos una serie de textos en los que Nietzsche parece demostrar un conocimiento profundo de las tesis spinozistas, más aún cuando se atreve a sentenciar -con bastante posterioridad a esta carta- que Fischer se equivoca en algunas de sus consideraciones sobre el sefardí. ${ }^{16}$ No cabe duda de que leyó atentamente lo que Fischer apuntaba sobre Spinoza, pero la óptica desde la que investiga el autor hegeliano y precursor del neokantismo denota una interpretación sesgada acerca de un sistema como este, tan alejado del tiempo de Nietzsche.

No obstante, creemos que partiendo de mediaciones alternativas podemos mantener el vínculo, aunque sea indirecto. Esta intención no pasa por alto las

\footnotetext{
CO IV, 135, 2012, pp. 143-144.

Véase Espinosa Rubio (2001), p. 66.

«Y por eso hoy quiero recordar, así pues, a un maestro de doctrina y de disciplina del que he de gloriarme, Arthur Schopenhauer - para en posteriores ocasiones recordar a otros». "Consideraciones intempestivas: Schopenhauer como educador", OC I, 2011, p. 752.

14 CO IV, 123, 2012, p. 135.

15 Contamos con cuatro fragmentos en su cuaderno de notas tomadas entre Primavera y Otoño de 1881, además de otras referencias que hace en diversas obras. Con respecto a las menciones que Nietzsche hace de Spinoza, el profesor Raúl de Pablos Escalante (2016) realiza una completa relación de las referencias en su artículo, notas 14 y 15 respectivamente.

16 “La genealogía de la moral”, II, §15, OC IV, 2016, p. 502.
} 
complicaciones para fundar una base sólida que nos permita entroncar con sus objetivos ontológicos y que pueda acercarse lo más posible a la solidez de esa primera conexión. Planteamos una base común y compartida con una tradición diferente, pero en la que encontramos fuertes parecidos de familia. Proponemos encontrar esta base en el pensamiento indio de la Advatia-Vedanta, ya que el pensamiento spinozista adquiere mayor nitidez desde esta óptica ${ }^{17} \mathrm{y}$ del que el sistema nietzscheano se ve influenciado por su tiempo. ${ }^{18}$ Pero antes debemos despejar algunas cuestiones que oscurecen esta comunicación intercultural.

Es algo común arrastrar el prejuicio reduccionista de considerar el sistema de Spinoza bien como un ateísmo, o bien como un naturalismo fuerte que deviene-desde la manida interpretación- en un panteísmo. Si nos dirigimos a su correspondencia con Oldenburg, vemos cómo expone y demuestra que ni su sistema es ateo, ${ }^{19} \mathrm{ni}$ que mucho menos pretende una identificación de Dios con la naturaleza. ${ }^{20}$

Spinoza expone su visión propiamente metafísica y el papel que juega Dios en su sistema en la primera parte de la Ética. Las partes siguientes las dedicará a plantear la relación de esta Sustancia infinita con los modos, frutos de su expresión y de la expresión de sus atributos en la naturaleza y el alma humana, el poder de los afectos y del entendimiento. Las lecturas que se han hecho al respecto han virado desde la posición más puramente idealista hegeliana hasta el materialismo marxiana, pero en lo que ambas coinciden es en el trasfondo monista del sistema.

A la luz de esto, hemos de entender que el sistema de Spinoza, que toma como eje principal la noción de Dios, no se pliega al esquema escolástico. Tampoco a la noción de Descartes, continuista con la tradición. Cuando Spinoza recurre a Dios en sus textos está hablando de una instancia primera de la realidad inmanente que acumula en sí misma y totaliza todo lo real en sus diferentes expresiones: «Por Dios entiendo un ser absolutamente infinito, esto es, una substancia que consta de infinitos atributos, cada uno de los cuales expresa una esencia eterna e infinita». ${ }^{21}$ Es decir, un Dios que no se sitúa fuera del mundo, porque es parte de él, y se expresa en cada uno de sus atributos, y estos a su vez en sus modos. Cada uno de esos modos, de los individuos y la naturaleza, es una expresión y relación de Dios o Naturaleza consigo mismo. Por lo que se entiende que este Dios se sitúa en una filosofía «infinitista» y de la «afectividad», no representacional, pues en tanto que es causa de todo y de sí mismo, todo es expresión y afección suya: en Dios «comienza la génesis eterna del mundo de los seres finitos». ${ }^{22}$

Spinoza abre un primer pensamiento revolucionario que rompe la relación entre la acción humana y el mysterium fidei: la noción de "Dios", tal y como se ha entendido en estos sistemas, es prescindible -aunque no lo es como entidad-.$^{23}$

\footnotetext{
Lenoir (2019), p. 96.

«Para bien o para mal, a partir del siglo XVIII, Europa se orientalizó». Maillard (2014), p. 651.

Véase Ep. 43, p. 287. Cfr. E1P11D, p. 67.

Véase Ep. 73, p. 387.

E1Def.6, p. 57.

Domínguez (2019): 282.

23 Es indudable que la existencia de Dios es necesaria en el pensamiento de Spinoza. Es el eje central de su sistema, así lo demuestra en la E1P15: «Todo lo que es, es en Dios, y sin Dios nada puede ser ni concebirse». Esto es innegable. Lo que nos resulta más difícil de afirmar es que otra concepción de "Dios" sea imposible en el sistema de Spinoza. Esto supondrá una de las claves para las críticas de la contrailustración. Con respecto a las concepciones teológicas de Occidente, su comparación con las orientales y profundizar en esto, véase Maillard (2014), p. 341 y Espinosa Rubio (1997), pp. 55-56/82.
} 
No es el Dios de la tradición, tampoco el Dios de Descartes que necesita apelar al rationabile obsequium; es la acumulación total de todo lo real: «el itinerario de la sabiduría no será pues una ascensión hacia el cielo, o al más allá indecible, sino una profundización de la existencia misma en nuestro único mundo, la Naturaleza». ${ }^{24} \mathrm{El}$ Dios de Spinoza es una metáfora trascendental que acumula y establece ese dominio inmanente y expresivo en la realidad como acumulación de todas las posibilidades ontológicas, naturales, afectivas, perceptivas y éticas de la realidad. Comprende la trascendencia del mundo a partir de su inmanencia, es decir, de su mundanidad y, por lo tanto, de la corporalidad. Es una realidad dinámica, pero que no escapa de sí mismo, pues nada hay fuera de lo real y de lo absoluto impersonal. ${ }^{25}$ Una propuesta como esta sería incomprensible desde la óptica de su tiempo, por ello necesitamos recurrir a esquemas fundamentales que desarrollen una hermenéutica consistente:

Lo que es evidentemente extraño y lejano adquiere, por una u otra razón, la categoría de algo más familiar. Se tiende a dejar de juzgar las cosas porque sean completamente extrañas o completamente conocidas; surge una nueva categoría intermedia, una categoría que permite ver realidades nuevas, realidades que se ven por primera vez como versiones de una realidad previamente conocida. En esencia, una categoría de este tipo no es una manera de recibir nueva información, sino un método para controlar lo que parece ser una amenaza para la perspectiva tradicional del mundo. ${ }^{26}$

En busca del conocimiento de los esquemas y del lugar cósmico de las cosas y las personas para entender su situación ontológica, guiada por los afectos, es donde el spinozismo y el vedismo se encuentran casi como un reflejo de sí mismos. Les une, a fin de cuentas, un conato de autoconocimiento de las propias potencias para entender nuestras capacidades constructivas y afectivas, activas y reactivas, en el mundo. De tal forma que conocemos lo trascendente desde lo inmanente en la unidad absoluta de lo existente, que encuentra su densidad ontológica en esa univocidad de lo real; unívoco, pero plural en sus modos de ser. Los modos no son meros accidentes de la Sustancia infinita, sino la base ontológica, epistemológica y corpórea de su existencia, pues en «cuanto más conocemos las cosas singulares, tanto más conocemos a Dios». ${ }^{27}$ Se trata de reconocer esa expresión que se da en la naturaleza, la relación afectiva y emocional de los seres humanos con el mundo.

Frédéric Lenoir formula esta comparación con claridad: «El camino de la sabiduría consiste en tomar conciencia de que el brahman y el atman no son más que uno, y que cada individuo es una parte del Todo cósmico». ${ }^{28}$ Ambos esquemas se formulan desde el reconocimiento de la inmanencia como principio de lo Absoluto. De esto se desprende un dinamismo de la Sustancia donde lo inmanente y lo trascendente juegan siempre en ese intercambio. La causalidad ontológica de lo real se encuentra en «lo divino impersonal» o brahman $^{29}$ y se expresa en cada uno de los modos individuales de la existencia. En este sentido, y tomando como base el modelo determinista que inunda al vedismo, el mismo orden lógico-ontológico de Spinoza -Substantia- en

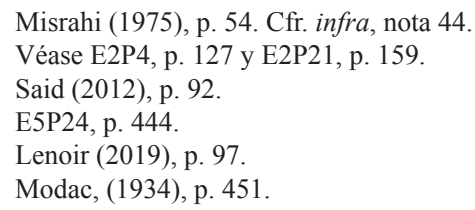


la Ética y del vedismo -Rita- en los Upanishads, se presentan como expresión de lo universal y lo absoluto bajo unas mismas leyes. La razón de lo individual -o atman- es parte de esa razón cósmica-Mahat-. Esta razón queda apresada bajo los dualismos que la desgarran y que no permiten la plenitud de las acciones si se siguen las limitaciones de lo condicionado-Maya-.

El dinamismo de la natura como expresión no es finalista, «pues, si Dios actúa con vistas a un fin, es que -necesariamente- apetece algo de lo que carece».$^{30}$ Esta natura es un todo absoluto que abarca todas las formas de lo real, y en tanto que se expresa en sus modos, se sigue una determinación a ser y existir. Ante esto, el sabio spinozista y vedista se sabe liberado de la dualidad en aras de la expresión de esa totalidad: «la alegría llega cuando hemos aprendido a armonizar nuestra naturaleza con la Naturaleza». ${ }^{31}$ Esta situación le permite el despliegue de todas sus capacidades o coartar sus impulsos, dependiendo del registro en el que se encuentre. El ser humano toma conciencia entonces de lo limitado de sus acciones y de su voluntad. Queda a merced del condicionamiento y confusión de las imágenes a través del desgarro de los dualismos que arrastran al cuerpo a la impotencia en el registro de Maya. La superación de esos dualismos que corrompen al ser humano y desgarran su situación en identidades opuestas, produciendo una esquizofrenia ontológica, pasa por traspasar o, mejor dicho, "aniquilar el velo de Maya».32 Las relaciones quedan fijadas en esa búsqueda de liberación de la vida como fuente de un impulso creativo para dar paso a un autoconocimiento de toda la realidad y la culminación estéticoemotiva de la existencia personal ante la liberación de la potencia-samsara-.

De este modo, Nietzsche canaliza la influencia de la imaginación según la filosofía india a partir del interés de su tiempo y su maestro por la cultura y pensamiento oriental. Y, de hecho, aun cuando Schopenhauer abordaba el pensamiento indio solo con una intención instrumental, ${ }^{33}$ su pupilo intelectual desarrolla un sistema mucho más acorde con las bases del pensamiento vedista:

El desorden, el caos, las ruinas, que no apuntan a la simetría y al equilibro más que por su carencia de ello, serían una expresión plástica en verdad más acorde con ella. La estética de la voluntad entendida como fuerza incontenible habría de ser la desproporción y la arracionalidad: una estética dionisíaca. ${ }^{34}$

Es por ello que una propuesta pesimista como la schopenhaueriana no tiene cabida aquí, algo que Nietzsche también reconoce. ${ }^{35}$ Pero no quiere decir que acepte los postulados de los Vedas, como apunta en una carta a Heinrich Köselitz, ya que guardan un fuerte contenido sacerdotal, pero, y he aquí lo importante, «no pesimista». ${ }^{36}$

Nos queda por ver en qué sentido esta fenomenología de lo que aparece como ilusorio ha de ser superada. Esa apariencia engañosa, el velo de Maya, no es del atman,

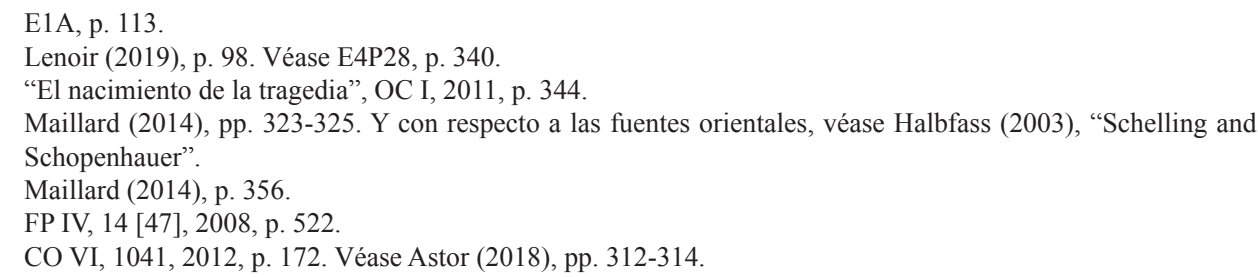


es del brahman, «él mismo se pone la venda en los ojos al dividirse». ${ }^{37}$ La unidad de lo real, que en ningún caso es reductiva a ningún plano en concreto, se nos presenta ante la conciencia de ese juego del brahman. En este sentido, para Schopenhauer es mediante el arte que llegamos a la contemplación de lo incondicionado como sujetos puros desprendidos de toda ansia de individualidad. El resultado de esto es que esta concurrencia «da lugar a ese tipo de satisfacción estética a la que denomina a fin de cuentas, "beatitud" [alegría]». ${ }^{38}$ Por medio de estas imágenes lo horrible se torna sublime y lo absurdo cómico. ${ }^{39}$

El sabio, el genio o el artista se hayan en la encrucijada ante la dimensión lúdica de lo Absoluto, de ese juego de velos del brahman para descubrir toda una realidad que no puede ser superada por la razón. Estamos ante una propuesta conjunta de la aceptación alegre de la vida como acontecer de sucesos potencialmente constructivos y destructivos. Simplemente, una filosofía de lo que hay, del mundo fenoménico. ${ }^{40} \mathrm{En}$ este sentido, la única emergencia que sale al encuentro de esta comunidad da lugar a una concepción estética del mundo en la que creación y destrucción se desarrollan por igual. Este juego permite entender esa constructividad como un acto afectivo de nuestras fuerzas emotivas más profundas.

\section{Voluntad creativa: lo que puede un cuerpo}

Entender una continuidad entre todos estos estadios es complejo por la diversidad de cuestiones que se tratan y los matices que pueden plantearse. Una tradición como la vedista, que concuerda en la posición reactiva a una fenomenología como la que se desprende de la teoría schopenhaueriana -y que Nietzsche rechaza-, requiere comprender el fundamento de ese sentido imaginativo de la realidad. Para ello, debemos añadir a lo hasta ahora dicho un análisis de los conceptos de «vida»y «cuerpo» que emerge de esa lectura. Esto no quiere decir que podamos adscribir sus propuestas a la filosofía oriental. Proponer algo así sería imposible. Spinoza no puede y Nietzsche ni puede, ni quiere. ${ }^{41}$ Aunque mucho menos se puede afirmar que este intento sea casual. Desde este principio comparativo intercultural, es posible entender un encuentro fundamental entre una filosofía de potencias y otra de fuerzas con una propuesta estética latente en la realidad vital y corporal del ser humano.

Tanto para Nietzsche como para Spinoza hablar de vida y cuerpo supone entender una relación intrínseca con el mundo, entendiéndolo como escenario donde acontecen todas las producciones, ideas y acciones humanas:

37 Maillard (2014), p. 331.

$38 \quad$ Ibid., p. 343. «Esta experiencia, que va de lo propio a lo ajeno y de lo ajeno a lo otro que es sí mismo en unidad, lo llamamos experiencia estética». Ibid., p. 304.

39 "El nacimiento de la tragedia", OC I, 2011, p. 363. Resulta curioso ver que "lo horrible" y "lo cómico" son prácticamente sinónimos de dos de los rasas "terrible" (bhayānaka) y "humorístico" (hāsya). Este aspecto ha sido ampliamente estudiado y puesto en relación con el pensamiento occidental del siglo XIX por Chantal Maillard. Lo interesante de esta teoría es que se vertebra sobre la experimentación del sentimiento en el espectador. Volveremos sobre esto más adelante. Véase Maillard (2014), pp. 283-292; Rasa. Palma de Mallorca, José J. de Olañeta, 2007; Rasa: el placer estético en la tradición india. Barcelona, Etnos, 1999.

40 Maillard (2014), p. 327. Cfr. Roldán López (2018), pp. 96-97.

41 Acerca de la posición de Nietzsche con la filosofía oriental y, más concretamente, con la figura de Buda, véase "Ecce homo", I, §6 (OC IV, 2011), p. 792. 


\begin{abstract}
¿Y sabéis qué es para mí «el mundo»? [...] Este mundo: una enormidad de fuerza, sin principio, sin fin, una grandiosidad sólida y férrea de fuerza, que no aumenta ni disminuye, que no se gasta, sino que sólo se transforma, en cuanto todo inmutablemente grande, una economía sin gastos ni pérdidas, pero asimismo sin crecimiento, sin ingresos, envuelto por la «nada» como por un límite, nada que se desvanezca, que se disipe, nada infinitamente extenso, sino en cuanto fuerza determinada, colocada en un espacio determinado y no en un espacio que estuviera «vacío» en alguna parte, antes bien en cuanto [...] juego de fuerzas y ondas de fuerza, a la vez uno y «múltiple» [...] un mar de fuerzas que se precipitan sobre sí mismas y se agitan, cambiando eternamente [...] desde el juego de las contradicciones hasta el placer de la armonía, afirmándose a sí mismo incluso en esa igualdad de sus trayectorias $[\ldots] .^{42}$
\end{abstract}

El mundo acontece de una determinada manera y las leyes que imperan son irreductibles a ningún poder dentro de ella. El ser humano y los demás modos se pliegan al juego de la natura en ese devenir constante de fuerzas en las que, a primera vista, solo acepta sus propias normas:

Puesto que el hombre, sea sabio o ignorante, es una parte de la naturaleza, y todo aquello por lo que cada individuo es determinado a actuar, debe ser atribuido al poder de la naturaleza en la medida en que este pueda ser definido por la naturaleza de este o aquel hombre. Porque, ya se guíe por la razón, ya por el solo deseo, no actúa sino en conformidad con las leyes o reglas de la naturaleza. ${ }^{43}$

Esto es cierto, como que ambos reconocen que el ser humano violenta tanto su propia condición como el poder natural que lo domina a través de su proyección racional sobre el mundo. Por ello Nietzsche entiende que «la cuestión de cuál de las dos concepciones del mundo sea más correcta carece totalmente de sentido, puesto que para ello habría que tomar como criterio la percepción correcta, esto es, un criterio del que no se dispone». ${ }^{44}$ De modo que la concepción materialista de Nietzsche puede chocar con una lectura superficial de la sustancia infinita para Spinoza. En este sentido, Belén Castellanos apunta:

El concepto de Dios [substantia] sirve para salir del representacionismo, para liberarnos de los esquematismos, para mostrar que la Naturaleza es inagotable, es tan cognoscible como incognoscible, es el conjunto de todas las posibilidades con una virtualidad desbordante. ${ }^{45}$

Ante la representación, ninguno de los dos autores se muestra convencido de que todo lo que en el mundo hay -o de lo que se dice o se cree que hay- sea como el propio mundo es; menos aun cuando reconocemos las representaciones de los valores que se imprimen en el mundo como ley natural: «Ficción de un mundo que corresponda a nuestros deseos, artificios psicológicos e interpretaciones para vincular con ese mundo verdadero todo lo que veremos y sentimos como agradable». ${ }^{46}$ Se colige que

\footnotetext{
$42 \quad$ FP III, 38 [12], 2010, p. 831. (La cursiva es nuestra.)

43 TP, II, $\S 5$, p. 86.

44 "Sobre verdad y mentira en sentido extramoral" OC I, 2011, p. 615.

45 Castellanos Rodríguez (2015), p. 389.

46 FP IV, 9 [60], 2008, p. 250.
} 
esas imágenes, ese velo, tienen un contenido onto-lógico. Las imágenes no son meras sombras de lo que en verdad es, sino proyecciones racionales que apuntan a un deseo latente. En este sentido, esas ficciones se presentan como entes vitales, es decir, como entidades epistémicas ontológicamente complejas. Se muestran como entes de razón. Por ello entendemos que «esos modos de pensar no son ideas de cosas ni pueden ser considerados como tales», pero el hecho de que hayan surgido de nuestra razón o, incluso, de nuestra voluntad a partir de lo que percibimos de la realidad, ha llevado a tomar por ideatum otra idea, «de ahí que incluso les hayan puesto nombres, como si significaran seres que existen fuera de nuestra mente». ${ }^{47}$ El gran teatro del mundo y las ficciones que en él se representan han servido al ser humano en su desarrollo, abrigándole con las categorías suprasensibles a las que ningún otro ser puede revelarse. Ante nuestra naturaleza precaria, comienza a desplegarse un instinto de supervivencia onto-lógico. Así se perpetúa ese impulso fisiológico hacia la continuidad, a mantenerse en el ser: «Pues yo te amo, oh, eternidad». ${ }^{48}$

Percibimos que en ambos hay una intención de unificar -que no reducir- lo existente, vindicando un inmanentismo radical que emana de un sentido telúrico del mundo y del que se desprende una concepción imaginativa del mismo que la razón imprime. ${ }^{49}$ Pero con ello no quieren decir que podamos fingir esos entes, sino que a partir de ese entramado racional podemos llevar a cabo actos mentales que nos permitan un acercamiento al mundo mediante la razón y sus categorías. ${ }^{50}$ Lo que ninguno de los dos niega es que hay un sentido que puede ser considerado de muchas formas -categorial, discursivo, fisiológico, histórico, etc.-, que está presente en el mundo y que tiene su principio en el ser humano. Si es posible llegar a un punto de encuentro entre ambas posturas acerca de una dimensión ficcional de la realidad, no es tanto para ver en qué sentido el mundo puede ser una imagen, sino cómo el ser humano ha creado ficciones imaginarias en el mundo para describirlo, nombrarlo y comunicarlo lógicamente. De esta forma, ese imprimatur de la razón «se puede llamar cómodamente ser verbal, puesto que solo se puede expresar con palabras [flatus vocis]». ${ }^{51}$ Pero,

¿qué es una palabra? La reproducción en sonidos articulados de un estímulo nervioso. Pero partiendo del estímulo nervioso, inferior además a una causa existente fuera de nosotros, eso ya es el resultado de un uso falso e injustificado del principio de razón. ${ }^{52}$

47 CM, I, I, p. 286. En este sentido, podemos entender esas ficciones como "entes de razón” y no como "entes de ficción" porque no negamos la existencia de esas imágenes, las reconocemos como creaciones imaginativas de la razón que intentan acomodarse al mundo. Spinoza reconoce que ninguna tiene existencia real. Entenderlas como "entes de ficción" supondría decir que cabe una posibilidad de que dicho ente, por casualidad o por acumulación de sus características, apuntase a una realidad, mientras que el ente de razón es «un modo de pensar, que sirve para retener, explicar e imaginar más fácilmente las cosas entendidas». Ibid., p. 284. Acerca del lugar de la imaginación en la filosofía de Spinoza, véase Espinosa Rubio (1997), pp. 73-74 e "Historia, naturaleza humana y experiencia: nociones transitivas", en Carvajal y de la Cámara (2008), pp. 353-369 y Domínguez (2019): pp. 221-246.

48 “Así habló Zaratustra”, III, 16, OC IV, 2011, p. 215. Cfr. E3P6, p. 220.

49 «Nietzsche no desprecia la razón, admira en ella la fuerza de un instinto, el trabajo de selección, de jerarquización y de creación que se efectúa con ella». Astor (2018), p. 201.

50 TIE, II, 1, [58], pp. 125-126.

51 CM, I, III, p. 295.

52 "Sobre verdad y mentira en sentido extramoral” OC I, 2011, p. 611. Cfr. Astor (2018), p. 198: «Esto significa también que "en el origen" el lenguaje es esencialmente sensible y no se funda en ninguna inteligibilidad». 
Las abstracciones universales que habían servido para el amparo del ser humano se descubren como entidades instrumentales para una mejor asimilación del mundo, subordinándolo a intereses particulares. Se descubren, por tanto, como metáforas de la voluntad. Como no hay una cosa-en-sí, ni mucho menos un mundo verdadero al cual denominar realidad-en-sí, «sino que siempre tiene que introducirse primero un sentido para que pueda haber un hecho», ${ }^{53}$ preguntar por las ideas, las relaciones y por la pregunta misma sobre la realidad de las cosas supone examinar nuestra capacidad estética de crearlas y realizarlas:

No es logos, sino pathos. Sin embargo, del lenguaje nacerá la razón, «de forma irracional», y éste es un enigma que habrá que descifrar. Sobre verdad y mentira evocará, pues, el tránsito, en la constitución de palabras, desde el orden metafórico (sensible) hasta el orden conceptual (inteligible): nueva traducción, nuevo salto a lo heterogéneo, nueva creación. ${ }^{54}$

El sujeto empieza a violentar la naturaleza al desplazar su relación con ella a un plano metafísico construido por la metáfora. Al desarrollar esta estetización de la violencia hacia la naturaleza, la relación sujeto-mundo alcanza una dimensión donde las posibilidades de desarrollo de esa creatividad entran en tensión, hasta que nos detenemos a observar que la misma naturaleza, escenario de creación y destrucción, se convierte en el modelo de las fuerzas. Por lo que las relaciones ni se mantienen ni se rompen, sino que entran en una nueva dimensión que aumenta la potencia del hombre por el escenario de creación y destrucción de la naturaleza: «Por estas dos fuerzas contrarias obra la naturaleza obra artísticamente sin mediación del hombre artista. Después vendrá la acción del hombre, muchas veces imitativa, creando un arte, pero las fuerzas dionisíaca y apolínea son la expresión de los poderes naturales». ${ }^{55}$ La naturaleza, en toda su diversidad, despliega todo un entramado de posibilidades que demanda nuevas legislaciones en el devenir, dando al ser humano un escenario creativo desde el que aumentar su potencia.

Por tanto, hablar de vida para estos autores supone apuntar de una fuerza artística al propio crecimiento y progreso. En suma: necesitan dotar de una nueva densidad ontológica a esta dimensión para que la inmanencia de la vida humana no caiga en formas abstractas. Spinoza no duda, Nietzsche aún menos: la realidad del ser humano como organismo vivo es un impulso, un conato vital y un apetito de superación; es voluntad de poder:

Este esfuerzo [conatus], cuando se refiere al alma sola, se llama voluntad, pero cuando se refiere a la vez al alma y al cuerpo, se llama apetito; por ende, éste no es otra cosa que la esencia misma del hombre, de cuya naturaleza se sigue necesariamente aquellas cosas que sirven para su conservación, cosas que, por tanto, el hombre está determinado a realizar. Además entre «apetito» y «deseo» no refiere generalmente a los hombres, en cuanto que son conscientes de su apetito, y por ello puede definirse así: el deseo es el apetito acompañado de la conciencia del mismo. ${ }^{56}$

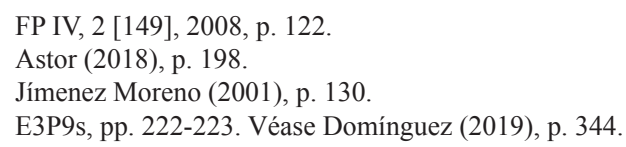


La proposición continúa, y veremos cómo lo hace más adelante, pero casi como en un diálogo con el sefardí, Nietzsche continúa añadiendo a esta proposición que:

Suponiendo que nuestro mundo de apetitos y pasiones sea lo único real que está «dado», que no podamos ascender o descender hacia ninguna otra «realidad» que precisamente la realidad de nuestras pulsiones - pues pensar es solo una interacción de esas pulsiones entre sí-: ¿no nos es lícito hacer el intento y plantear la pregunta de si este estar dado no bastaría para comprender también, partiendo de lo idéntico a sí mismo, el llamado mundo mecánico (o «material»)? No me refiero a comprenderlo como ilusión, como «apariencia», como «representación», sino como algo dotado de un mismo grado de realidad que nuestro afecto mismo, -como una forma más primitiva del mundo de los afectos, en la que todo está dispuesto todavía en una poderosa unidad que luego se ramifica y configura en el proceso orgánico como una suerte de vida pulsional en la que todas las funciones orgánicas, la autorregulación, la asimilación, la nutrición, la excreción y el metabolismo, siguen estando sintéticamente unidas entre sí, -¿cómo una forma previa de la vida?-. ${ }^{57}$

Las miras no están puestas en conservar al ser, sino en acumularlo y aumentarlo para extralimitar los condicionamientos que sitúan al individuo en el mundo. Sin embargo, el sujeto no cuenta con la legitimidad para sobreponer sus fuerzas a las del mundo, por ello la respuesta es doble: hermenéutica y estética; interpretativa y creativa. Pero, por la forma en que ambas se expresan, podrían reducirse a la segunda. La vida se define «como una forma duradera de múltiples procesos de tomas de posición de fuerzas en la que lo esencial es el poder de crear formas, es decir, de interpretar, de estimar, de evaluar sin más finalidad ni meta que la de conservar y acrecentar de ese modo su fuerza». ${ }^{58}$

El problema reside en la óptica que tomamos a la hora de abordar el problema. Foucault asume esta cuestión, y señala que el problema atañe al principio mismo desde el que nos posicionamos en las cuestiones de este tipo. No podríamos hacerlo atendiendo al origen, que no puede adecuarse a la naturaleza de estas ficciones, sino desde la raíz inmanente de la procedencia. Acercarnos a esta procedencia parece recurrir a un escenario que se muestra a veces oscuro por las racionalidades que lo han sepultado y que han querido negarlo en la búsqueda de lo originario, por ello Foucault resuelve que el lugar más claro donde todas las ficciones, discursos y construcciones apuntan y proceden atañe al propio cuerpo. ${ }^{59}$ La recurrencia al cuerpo en este plano no solo es compartida por Nietzsche y Spinoza, sino que reconocen una confluencia de sentidos que parten de lo corpóreo al tenerlo como fuente de todas nuestras realidades:

el cuerpo es dinámica de fuerzas de una mayor sutileza e inteligencia. Tiene la seguridad innata de un funcionamiento autónomo y una sabiduría que está por encima de nuestro saber consciente, y que hace de lo corporal, en cierto modo, una conciencia de rango superior al yo. ${ }^{60}$

\footnotetext{
“Más allá del bien y del mal”, §36, OC IV, 2011, p. 322.

Sánchez Meca (2005), p. 150.

Foucault (1988)., p. 30.

Sánchez Meca (2013), p. 108.
} 
Con arreglo a estas notas, que toda genealogía descubre en el cuerpo, reconocemos su aportación en un juego de formas, de trazos epidérmicos que (a)parecen (al) seguir una lógica constantemente presente en el discurso de la razón dominadora, que no solo violenta al mundo, sino al propio cuerpo. Una hermenéutica de la corporalidad podría coincidir, en el sentido en que para Spinoza lo micro y lo macro se reconocen, con una hermenéutica del mundo y, en este sentido, de nuestra operatividad y creatividad desde el cuerpo. El cuerpo se presenta como el mapa de nuestras vivencias, pero también como el plano de nuestros deseos y afecciones; como la cartografía de toda voluntad de poder:

De acuerdo con mi representación, cada cuerpo específico aspira a dominar el espacio entero y a extender su fuerza (-su voluntad de poder:) y a repeler todo lo que se opone a su expansión. Pero tropieza constantemente con aspiraciones iguales de otros cuerpos y acaba arreglándose («uniéndose») con aquellos que le son bastante afines: -así conspiran entonces juntos para lograr el poder. Y el proceso continúa... ${ }^{61}$

El estado de pluralidad y de apertura del cuerpo a su natural estado creativo nos introduce en un estadio de indeterminación: «nadie, hasta ahora, ha determinado lo que puede el cuerpo». ${ }^{62}$ Pero no de incertidumbre, pues encuentra en sí mismo todo punto de referencia para poder seguir construyendo acorde con su voluntad. El cuerpo no puede cesar de contribuir en sus actos creativos, de los cuáles surgen las relaciones con otros cuerpos y, de esta forma se crea un continuum que, o se expresa, o muere con la voluntad y el cuerpo. Por tanto, el cuerpo no solo está sometido a las leyes de la naturaleza, sino que se proyecta como artífice artificial y punto de encuentro de las diversas creaciones: «El hombre es una multiplicidad de "voluntades de poder": cada una con una multiplicidad de medios expresivos y formas». ${ }^{63}$

Consecuentemente, el cuerpo se presenta como lugar de encuentro y de sentido, pero que no pasa por alto su singularidad como cuerpo que crea y es creado desde una subjetividad y voluntad concreta. La estética -o capacidad de crear formas estéticamente-, en el momento que se descubre como acción del cuerpo, se convierte en un instinto de creación. «El fenómeno "artista" sigue siendo el más transparente: ¡desde ahí, mirar los instintos fundamentales de la fuerza, de la naturaleza, etc.! ¡De la religión y la moral también!». ${ }^{64}$ De lo que se deduce que lo expresado por el arte es, por su propia naturaleza, expresión de toda la realidad. En suma: en una dimensión radical de afectos y deseos que quedan marcados en la memoria de la piel como muestra de su poder constructivo.

\section{Afectividad constructiva}

Hemos de tener en cuenta que la propuesta de Nietzsche acerca de la voluntad de poder es el producto de un análisis de su tiempo:

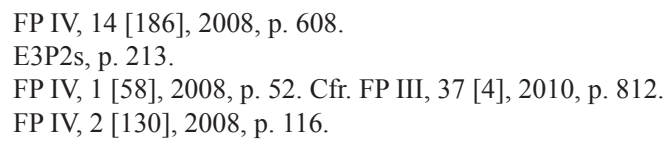


si el hombre va a liberar una prodigiosa fuerza creativa para capturar lo incapturable y nombrar lo innombrable, ello se debe a que el devenir universal es mortalmente peligroso para su instinto de conocimiento (es decir, para su voluntad de dominio y apropiación del mundo). ${ }^{65}$

Esa voluntad resalta y aparece como indudable cuando constatamos que hay una sintomatología psicológica que se presenta arrasadora ante los conceptos y sentimientos occidentales: «Nihilismo significa entonces la interiorización del encadenamiento histórico de los diferentes momentos en los que la voluntad de poder se niega a sí misma, se rechaza como afirmación», pero que, «tras descender a los grados más bajos de negación, vuelve a hacerse afirmativa». ${ }^{66}$ Es una dialéctica que deviene negativa por el resultado de lo que el mundo le devuelve, pero que se supera ante las capacidades creativas del cuerpo. Aún más, encuentran en la moralidad una obra absolutamente original:

la moral, como el arte, brota del cuerpo y sus productos actúan luego sobre el cuerpo aumentando o disminuyendo su fuerza en función de si sirven a la expansión de la vida o a su negación. ${ }^{67}$

En este sentido, ambos autores identifican todas estos entes como artificios del racionalismo metafísico: «Todas las cosas que hay en la naturaleza, son o cosas o acciones. Ahora bien, el bien y el mal no son cosas ni acciones. Luego el bien y el mal no existen en la naturaleza». ${ }^{68} \mathrm{El}$ dominio de la razón occidental, con un logos propio y determinado, inscribe dichas determinaciones no ya solo en el mundo como escenario indiferente, sino en el ser humano como pieza clave en el mecanismo dominador de las representaciones: «así nacen el bien y el mal: la determinación ética, de lo bueno y lo malo, se desplaza por el juicio moral». ${ }^{69}$ La representación ha absorbido al individuo, convirtiéndolo bien en representación de otro, bien en su propia representación reguladora. El ser humano pasa a ser, en sentido corpóreo y ético, su propia obra de arte a fuerza de razón instrumental.

Aparece una dificultad cuando el planteamiento spinozista no parece concordar en este sentido con la concepción de una razón instrumental fuerte como la que propone Nietzsche, llegando a poner en serios problemas este paso -necesariamentecomparativo. Como bien ha señalado Inmaculada Hoyos Sánchez: «La potencia [...] hay que entenderla en el sentido de vigor y de fuerza, de dynamis y de vis, para existir y no para dominar. Y así la potencia no es equivalente al poder». ${ }^{70} \mathrm{Y}$, desde ese punto de vista, es incuestionable. Pero creemos que, si queremos abordar esta dimensión acerca de la fuerza de nuestras pasiones creativas que tienen su procedencia y punto de apoyo en el cuerpo, es necesario entender la perspectiva desde el lugar en que esa fuerza o deseo se expresa y determina a la voluntad de poder.

Entendemos la dimensión razón-pasión desde una óptica que concibe a la razón que se proyecta, que se muestra dominadora, no está reñida con una pasión dominante.

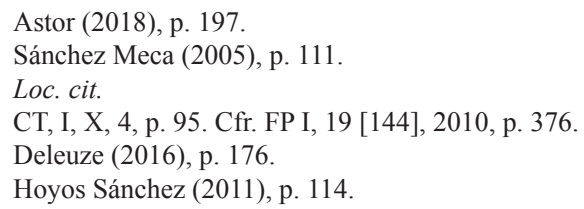


Al entenderla como dominadora supone representar esa proyección como un acto externo, es decir, una fuerza que se proyecta hacia lo Otro: «Nos esforzamos cuanto podemos por conseguir que la cosa amada sea afectada de una alegría acompañada de la idea de nosotros mismos, esto es por conseguir que nos ame a su vez». ${ }^{71}$ Así, la razón dominadora sale de sí con vistas a hacerse con un mundo que toma bajo la óptica del engaño, dejándose controlar por los velos y las metáforas creadas por el deseo de su voluntad y haciéndolas pasar por sus verdaderas razones. No puede haber poderío allí donde la única realidad es la contingencia de las ficciones o pasiones inadecuadas, que no hacen crecer la propia autodeterminación. Por ello, al acertado planteamiento de la profesora Hoyos Sánchez queremos añadir esta distinción que refuerza el argumento y dota a esa potencia o fuerza de una capacidad de autoconocimiento y de proyección, tanto hacia fuera como hacia dentro:

La fuerza y el incremento de una pasión cualquiera, así como su perseverancia en la existencia, no se define por la potencia con que nosotros nos esforzamos por perseverar en existir, sino por la potencia de la causa exterior, acompañada de la nuestra. ${ }^{72}$

Entendiéndolo en este sentido, como una potencia que incluye también a la pasión, podemos circunscribir a esta pasión la dimensión de poder de lo Otro. La posibilidad de esto radica en que la apetencia que alimenta las pasiones para Spinoza no tiene un sentido puramente metafísico, sino que está basado en una doble conciencia: la perseverancia en el ser y en su capacidad de aumentarlo, de colmarlo de alegría. De esta forma, defender que el arte sea «estimulante de la voluntad de poder» ${ }^{73}$ acompaña a la ruptura de toda pretensión de ascetismo que venía impuesta por la razón dominadora de la tradición y por la negación schopenhaueriana, pasando ahora a un estadio alternativo en el que los binomios se rompen y entrecruzan su potencialidad dentro de la creatividad ético-estética. Esta ética y estética de las pasiones sigue, por su sentido creativo, una operación que sitúa al individuo en un escenario en el que se dan las condiciones de posibilidad para que el deseo pueda satisfacerse en aras de la autoafirmación y del crecimiento de la voluntad. En palabras de Spinoza:

Mientras el alma imagina aquellas cosas que aumentan o favorecen la potencia de obrar de nuestro cuerpo, éste es afectado por modos que aumentan o favorecen su potencia de obrar. $^{74}$

La voluntad despliega en este sentido todo su potencial, pero no entendiéndolo en un sentido de dominio dañino o negador. Hemos de entender esta voluntad de dominio, que afecta y es afectada en aras de aumentar su potencialidad y su ser en un determinado sentido, disociándola de posturas bélicas y aproximarla a una posición del reconocimiento: «De modo similar a lo que ocurre en el caso de la idea de "belleza", la más alta voluntad de poder supera los contrastes sin necesidad de usar ya de violencia, esto es, sin negar o anular al otro, sino por afirmación superior de sí», pues no es un dominio reductivo, sino constructivo y copulativo. Se ha podido

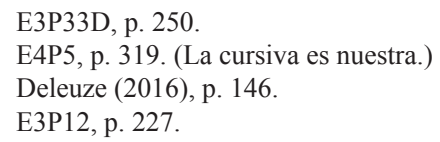


interpretar o, incluso, representar como una negación de aquello que afecta o a aquello a lo que se quiere afectar, deviniendo en imposición negadora, «cuando se trata más bien de una seducción: pues la actividad de la Wille zur Macht tiene más de conquista amorosa que de conquista militar». ${ }^{75}$

Las fuerzas se reconocen porque quieren expresar su poderío. La forma en que lo hagan podrá diferenciarlas, pero les une un nexo de seducción que ha llevado a dichas fuerzas concretas a individualizarse mutuamente entre las demás. Lo que implica esto es abrir un escenario donde se da un reconocimiento del poder afirmativo y constructivo de las fuerzas, por lo que estas fuerzas no podrán negarse mutuamente en el momento de la realización de su voluntad. Algo así apunta a la unidad de las potencias en el ejercicio de su dominio, activo o reactivo, tanto a las demás fuerzas como a sí mismas en un constante impulso corporal de satisfacción. Las fuerzas se definen entre ellas, no hay una posición dada de antemano, sino que ambas se posicionan a la vez que construyen su autodeterminación.

Un sistema de los afectos de este modo construido, con la voluntad de poder como pilar maestro, seduce solo con su planteamiento para adelantarnos tímidamente a sus contornos, pero sin poder evitar el impulso que mueve la mirada y la excitación al posarse sobre una construcción en la que el afecto creativo se vuelve erótico:

este amor [...] debe orientarse hacia la creación de algo que esté por encima de él y así, en cuanto «flecha del anhelo hacia la otra orilla», debe estar al mismo tiempo profundamente emparentado con una voluntad de ocaso [...] solo que dicho ocaso del subiectum, al remontar hacia otras riberas y procurar otros márgenes, posibilita el genuino egoísmo de la salud, el verdadero amor propio [Philautia $]{ }^{76}$

Este desplazamiento ha introducido en escena un punto de vista que unifica todos los intereses de la voluntad en un afecto que no solo conserva todas las intenciones de lo que hasta ahora habíamos dicho, sino que desborda todas las capacidades por esa inclinación creativa. Este movimiento atañe al deseo en el sentido mismo de su operatividad: contener todas las disposiciones posibles para aumentar su proyección a lo deseado. Para alcanzar esta posición, el afecto solo ha tenido que aceptar el condicionante de adecuarse a lo que el propio cuerpo permita, ${ }^{77}$ pero sin desistir en sus ansias de crecimiento. El enraizamiento en la dimensión ineludible de lo corpóreo faculta a este afecto a posicionarse y a reconocerse como afecto artístico cargado de erotismo:

todo lo que sea perfecto y bello como recuerdo inconsciente de ese estado de enamoramiento y de su modo de ver - toda perfección, toda la belleza de las cosas vuelve a despertar, por contiguity, la bienaventuranza afrodisíaca. Fisiológicamente: el instinto creador del artista y la distribución del semen en la sangre... La aspiración al arte y la belleza es una aspiración indirecta a los éxtasis del impulso sexual que éste transmite al cerebrum. El mundo que se ha vuelto perfecto, por el «amor»... ${ }^{78}$

\footnotetext{
Barrios (1990), p. 77. (La cursiva es nuestra). Cfr. FP IV, 9 [79], 2008, p. 256.

Ibid., p. 57. (La cursiva es nuestra). Véase E4P37s1, pp. 353-354.

E5P34, p. 451.

FP IV, 8 [1], 2008, p. 228.
} 
Siguiendo la tesis ordine cupidineo demonstrata, la pasión dominante requiere de unos fundamentos, necesita del amado y el amante. El objeto de deseo lo es solo en apariencia, pues el afecto reconoce la otra subjetividad, si no, sería mero control. El erómenos ama y desea, mediante su voluntad crea un escenario donde se desarrollan los afectos. Su imposición pasional de dominación adquiere consistencia bajo los mecanismos de la razón dominadora. Pero, a la vez, lo amado determina el alcance y límites de las pasiones y los afectos con su posicionamiento. El agente amante conforma a lo amado, pero si existe una voluntad dominadora sobre sí, es porque lo amado lo permite en este acuerdo lúdico, estableciendo los límites del deseo. El objeto se vuelve sujeto de deseo:

El amor nace, pues, del concepto y del conocimiento que tenemos de una cosa. $\mathrm{Y}$ cuanto mayor y más excelente se demuestre que es esa cosa, tanto mayor también es en nosotros el amor. ${ }^{79}$

En este sentido, las fuerzas chocan cuando las voluntades tratan de abrir nuevas legislaciones de la afectividad donde deben mostrarse en un estado de creación comunicativa simétrica. Es una creación estética para que el deseo siga avanzando en el aumento de su poder y de su alegría vital: «Es verdad: amamos la vida no porque estemos acostumbrados a la vida, sino porque estamos acostumbrados a amar». ${ }^{80} \mathrm{El}$ deseo de eternidad del afecto mueve su conatus al incesante desborde de sensaciones eróticas que reporten en la voluntad un estado de alegría poderosa.

De modo que los roles binarios no pueden instituirse aquí como formas esenciales del afecto al no adscribirse a la plasticidad de expresiones en ese espacio del deseo. El erastés abandona su lugar como dominador activo de la escena, reconociendo y aceptando sus límites en el juego de la seducción cuando el erómenos se los marca. Este es el transparente juego de la voluntad, en el que erómenos y erastés reconocen una misma voluntad seductora e impositiva en este espacio lúdico de lo erótico. Un espacio afectivo y de cuidados donde todo queda suscrito al deseo, afirmación y reconocimiento de los amantes.

Hay lucha, pero sin negar nunca la propia disposición de afectar y de ser afectado. La voluntad no solo dibuja sus acciones, sino sus escenarios de afectividad. La pugna queda dentro de la estética en tanto que se funda en el gesto creativo de las voluntades por la seducción. De modo que no hay moral anterior a ello, por eso mismo detonan los esquemas en una estética afectiva como esta, haciendo que las trascendencias se presentan innecesarias. Por todo ello, este erotismo detona esa violencia al mostrar que no puede doblegar el ansia de poder del cuerpo:

¿iNo es temible convertir sensaciones que son necesarias y regulares en fuente de congoja $[\ldots] ? !$ ¿iPuede llamarse enemigo a Eros?! Las sensaciones sexuales, al igual que las de la compasión o la veneración, tienen en común que una persona hace bien a otra gracias al placer que siente. ${ }^{81}$

CT, II, 5, [3], p. 110.

"Así habló Zaratustra", I, 7, OC IV, 2011, p. 93.

“Aurora”, §76, OC III, 2011, p. 529. 
Es la continuación de la proposición 9 de la tercera parte de la Ética:

Así pues, queda claro, en virtud de todo esto, que nosotros no intentamos, queremos, apetecemos ni deseamos algo porque lo juzguemos bueno, sino que, al contrario, juzgamos que algo es bueno porque lo intentamos, queremos, apetecemos y deseamos. ${ }^{82}$

La voluntad se afirma y supera a sí misma yendo más allá de las categorías de la razón práctica trascendental: entra en la dimensión de la cupiditas para blindar una relación estético-afectiva con otras voluntades de poder. En otras palabras: entra en la dimensión del deseo para crear estéticas desde el afecto, estéticas que permitan a las fuerzas artistas relacionarse eróticamente entre ellas y ejercer mutuamente su poder de seducción: «Lo que hacemos por amor ocurre siempre más allá del bien y del mal». ${ }^{83} \mathrm{El}$ despliegue de la fuerza de dominio no es más que su capacidad de seducir a las otras fuerzas. Lo hace porque la voluntad que la acompaña está dotada de una sensibilidad estética que le confiere una creatividad que solo se limita en tanto voluntad de un cuerpo creador y a la vez creado.

\section{Conclusiones}

A lo largo de estas páginas hemos querido plantear una serie de nexos entre Spinoza y Nietzsche partiendo de la idea de que ni Spinoza es un filósofo de la voluntad irracional como Nietzsche, ni Nietzsche es un pensador de la sustancia como Spinoza. Apuntamos a que plantear alguno de esos dos supuestos es problemático, pues podemos caer en el error de introducir una tendencia radicalmente materialista en Spinoza y a un Nietzsche defensor de sustancias metafísicas. Aunque sea cierto que divisamos una tendencia materialista en el holandés y una defensa de la voluntad como fuerza ontológica en Nietzsche, no podemos llegar al extremo de considerarlos inequívocamente iguales. Esto no implica que no podamos trazar puentes entre ambos autores a partir de una serie de puntos en común extraídos de sus planteamientos respectivamente intempestivos. Recurriendo a elementos filosóficos compartidos, una propuesta como base desde el pensamiento vedista puede proponerse como mediación entre ambos autores. Desde un estudio comparativo con las líneas del pensamiento spinozista y el vedista, siguiéndole la recuperación que en muchos puntos hace Nietzsche de estas doctrinas por su influencia schopenhaueriana, es posible esbozar un nexo que nos permite dibujar ese mapa que une a Spinoza y Nietzsche.

A partir de ahí vemos cómo una compensación de posturas abre toda una serie de posibilidades y vías de problematización que, dirigidas al ámbito estético, nos reportan un diálogo en el que surge la afirmatividad como eje principal de ambos planteamientos. Que podamos extraer de esa lectura intercultural un encuentro afirmativo -vitalista-, con todos los pormenores que de ello resulte, nos permite continuar con un itinerario practicable desde el pensamiento nietzscheano, introduciéndonos enseguida en la dimensión de la voluntad como impulso creador.

Los conceptos que surgen a partir de aquí se hacen patentes desde esta proyección

E3P9s, p. 223. Cfr. CT, II, §8, pp. 89-90.

“Más allá del bien y del mal”, §153, OC IV, 2011, p. 350. 
de la voluntad, más aún si entendemos esta voluntad como impulso de un afecto. El impulso inicial se torna afectivo cuando de esa mirada ético-estética desde los márgenes del pensamiento de Spinoza y Nietzsche reporta un producto tan complejo, pero a la vez tan simple, como es el hecho de hablar de una estética afectiva como reconocimiento de la voluntad en su situación dominadora y dominante. Los esquemas binarios se rompen desde esta posición. Todo queda aunado por el pathos estético que construye nuevas legislaciones para el desarrollo de la voluntad. De este modo, la voluntad afectiva se reconoce en un estadio erótico donde la voluntad de dominio, de unión y perseveración, quedan recogidas en su registro. No quiere abandonar nada y que nada lo abandone, no si no es para el aumento de su poder, es decir, el desarrollo constante e infinito de la alegría.

\section{Referencias bibliográficas}

Astor, D. (2018): Nietzsche. La zozobra del presente, Barcelona, Acantilado.

Barrios, M. (1990): La voluntad de poder como amor, Barcelona, Ediciones del Serbal.

Carvajal, J. y Cámara, M. ${ }^{a}$ L. de la (2008): Spinoza: de la fisica a la historia, Cuenca, Ediciones Universidad de Castilla-La Mancha.

Castellanos Rodríguez, B. (2015): El inconsciente ontológico de Gilles Deleuze, Madrid, Dykinson.

Deleuze, G. (2004): Spinoza: filosofía práctica, Buenos Aires, Tusquets.

Deleuze, G. (2016): Nietzsche y la filosofia, Barcelona, Anagrama.

Domínguez, A. (2019): Spinoza. Vida, escritos y sistema de filosofía moral. Madrid: Guillermo Escolar.

Espinosa Rubio, L. (2001): "Spinoza y el cristianismo". Cuadernos salmantinos de filosofia, 28, pp. 65-78.

Foucault, M. (1988): Nietzsche, la genealogía, la historia, Valencia, Pre-Textos.

Halbfass, W. (2003): “Schelling and Schopenhauer”, en A. L. Macfie (ed.), Eastern Influences on Western Philosophy: A Reader, Edinburgh, Edinburgh University Press, pp. 161-186.

Hoyos Sánchez, I. (2011): "La ontología naturalista de Spinoza como ontología de la pasión". Logos. Anales del Seminario de Metafisica, 45, pp. 95-122.

Jara, J. (1998): Nietzsche, un pensador póstumo. El cuerpo como centro de gravedad, Barcelona, Anthropos/Universidad de Valparaíso.

Jiménez Moreno, L. (2001): Nietzsche: Antropología y Nihilismo, Valencia, Universidad Politécnica de Valencia.

Lenoir, F. (2019): El milagro Spinoza. Una filosofia para iluminar la vida, Barcelona, Ariel. Maillard, Ch. (2014): India, Valencia, Pre-Textos.

Misrahi, R. (1975): Spinoza, Madrid, Edaf.

Modak, M. S. (1934): "Spinozistic Substance and Upanishadic Self: A Comparative Study". Philosophy, 6, 24, pp. 446-458.

Nietzsche, F. (2008-2010): Fragmentos póstumos, Madrid, Tecnos. 4 vols.

Nietzsche, F. (2011): Obras completas, Madrid, Tecnos. 4 vols.

Nietzsche, F. (2012): Correspondencia, Madrid, Trotta. 6 vols.

Pablos Escalante, R. de (2016): "La voluntad como deseo consciente: Kuno Fischer entre Spinoza y Nietzsche". Anales del Seminario de Historia de la Filosofia, 1, pp. 137-161.

Roldán López, C. (2018): "Nietzsche con Spinoza: estética de la inmanencia y potencia artística del pensamiento". Claridades. Revista de filosofia, 10, pp. 93-105. 
Said, E. W. (2012): Orientalismo, Barcelona, Debolsillo.

Sánchez Meca, D. (2005): Nietzsche. La experiencia dionisíaca del mundo, Madrid, Tecnos. Sánchez Meca, D. (2013): "Psicofisiología nietzscheana del arte y de la decadencia", en Rivera de Rosales, J. y López Sanz, Mª C.: El cuerpo. Perspectivas filosóficas, Madrid, UNED.

Spinoza, B. (1988): Correspondencia, Madrid, Alianza.

Spinoza, B. (1990): Tratado breve, Madrid, Alianza.

Spinoza, B. (2013): Tratado político, Madrid, Alianza.

Spinoza, B. (2014): Tratado de la reforma del entendimiento. Principios de la filosofía de Descartes. Pensamientos metafísicos, Madrid, Alianza.

Spinoza, B. (2016): Ética demostrada según el orden geométrico, Madrid, Alianza. 